Bol. Soc. Bot. México 50:43-68 (1990

\title{
La familia Rubiaceae en la región de Los Tuxtlas, Veracruz, México.
}

\author{
DAVID H. LORENCE ${ }^{1}$ y GUILLERMO IBARRA-MANRÍQUEZ ${ }^{2}$
}

\begin{abstract}
RESUMEN. En este trabajo se elaboró una clave de identificación para 96 especies (incluidas en 36 géneros) de la familia Rubiaceae presentes en la región de "Los Tuxtlas". Se discuten aspectos básicos sobre su distribución geográfica e importancia económica, asi como la revisión bibliográfica sobre los principales trabajos florístico-taxonómicos realizados para la familia en el área del sur de México. Los géneros con mayor número de especies son Hoffinannia (8), Psychotria (27), Randia (10) y Rondeletia (7).
\end{abstract}

ABSTRACT. In this work a key is presented to assist in the identification of the 96 species (comprising 36 genera) of Rubiaceae occurring in the "Los Tuxtlas" region of Veracruz, Mexico. Some basic aspects of the geographic distribution and economic importance of the Rubiaceae are presented together with a bibliographic revision of the main taxonomic and floristic works dealing with the family in the area of southern Mexico. Genera with the greatest number of species are: Hoffmannia (8), Psychotria (27), Randia (10), and Rondeletia (7).

La familia Rubiaceae es una de las más grandes dentro de las angiospermas: comprende aproximadamente 7000 especies distribuidas en alrededor de 500 géneros (Heywood, 1985). Aunque las especies de esta familia abundan principalmente en las regiones tropicales y subtropicales del mundo, es posible localizarlas también en partes frías y templadas, habitando páramos y zonas frías del norte de Canadá y Europa. Con una distribución predominantemente pantropical en la flora actual, existen pocas dudas en el sentido de que las rubiáceas tuvieron su mayor evolución en los trópicos, posiblemente en el Triásico o Jurásico, seguida de una radiación en ambientes extratropicales

1 National Tropical Botanical Garden, P.O. Box 340. Lawai, Kauai, Hawaii 96765, U S A.

2 Estación de Biología Tropical Los Tuxtlas, Instituto de Biología, Universidad Nacional Autónoma de México, Apdo. Postal 94, San Andrés Tuxtla, Veracruz, México. Dirección actual: Apdo. Postal 22-733. México 22, D. F. 
durante el Cretácico (Lee y Rink, 1985). En la zona Mesoaméricana, que abarca desde Chiapas y la Península de Yucatán (México) hasta Panamá, la familia cuenta con alrededor de 110 géneros y aproximadamente 1200 especies (John D. Dwyer, comunicación personal).

En México, las rubiáceas están representadas por unos 80 géneros nativos y cerca de 500 especies que incluyen hierbas como Coccocypselum spp., arbustos como Randia spp., árboles que alcanzan hasta 25 m como Elaeagia uxpanapensis, (Lorence, 1983), trepadoras como Manettia reclinata y lianas como Randia retroflexa (Lorence y Nee, 1987). Los miembros ubicados dentro de la familia, pueden ser caracterizados por sus hojas opuestas, simples, sin glándulas, con estípulas inter- o intrapeciolares, flores bisexuales (raramente unisexuales), con ovario ínfero y corola simpétala, usualmente regular. Sin embargo, pueden ser fácilmente confundidos con especies de otras familias de Angiospermas que posean hojas opuestas y simples. Las rubiáceas pueden diferenciarse entonces por los caractéres proporcionados en el cuadro 1.

Las especies de Rubiaceae son elementos conspicuos en todos los tipos de vegetación presentes en la República Mexicana. Son especialmente abundantes en comunidades tropicales, particularmente en los estratos medianos y bajos de la selva alta perennifolia (Miranda y Hernández X., 1963) y bosque mesófilo de montaña (Rzedowski, 1978), destacándose al respecto los géneros Hoffmannia, Psychotria, Randia y Rondeletia. Sin embargo, es necesario señalar que muchas especies pertenecientes a estos géneros son aparentemente muy semejantes entre sí, dificultando su identificación para personas sin experiencia en la determinación de la familia o sin acceso a la literatura existente sobre Rubiaceae. Con respecto al último punto, para la mayoría de las especies mexicanas existen sólo descripciones aisladas o bien, publicaciones dispersas y/o difíciles de conseguir localmente (Hampshire y Sutton, 1988).

Por estas razones, presentamos esta contribución sobre el conocimiento de las especies de Rubiaceae encontradas en la región de "Los Tuxtlas", la cual incluye información que intenta facilitar su identificación, básicamente por medio de una clave que utiliza caracteres de fácil observación en el campo y en ejemplares de herbario. Esta publicación se originó del trabajo de Ibarra-Manríquez (1985) y el proyecto a cargo del primer autor, sobre las rubiáceas de Veracruz.

\section{FITOGEOGRAFÍA}

En la distribución de los géneros de Rubiaceae que se encuentran en México, es posible detectar tres patrones principales. El patrón más común incluye géneros como Psychotria, Randia y Rondeletia, que se extienden desde Centro y Sudamérica hacia partes tropicales o subtropicales de México. Un patrón menos frecuente es el presentado por géneros como Galium y Relbunium, cuyo centro de distribución se inicia desde Norteamérica hacia porciones más sureñas de América. Finalmente, es posible agrupar 
Cuadro 1. Características para distinguir Rubiaceae de otras familias con hojas simples y opuestas."

\begin{tabular}{|c|c|c|c|c|c|c|c|}
\hline FAMILIA & $\begin{array}{l}\text { VENACION } \\
\text { HOJAS }\end{array}$ & $\begin{array}{l}\text { GLANDULAS } \\
\text { PELUCIDAS } \\
\text { EN HOJAS }\end{array}$ & ESTIPULAS & $\begin{array}{l}\text { TIPO } \\
\text { FLORES }\end{array}$ & $\begin{array}{l}\text { TIPO } \\
\text { COROLA }\end{array}$ & $\begin{array}{c}\text { SIMETRIA } \\
\text { COROLA }\end{array}$ & $\begin{array}{c}\text { POSICION } \\
\text { OVARIO }\end{array}$ \\
\hline CAPRIFOLIACEAE & PE & A & $A_{0} P$ & B & S & l,R & $\mathbb{N}$ \\
\hline GESNERIACEAE & PE & A & A & B & $S$ & 1 & IN,SU \\
\hline LABIATAE & PE & A & A & B & S & 1 & SU \\
\hline LOGANIACEAE & PE & A & $A_{0} P$ & B & s & 1 & SU \\
\hline MELASTOMATACEAE & TR & A & A & B & PO & $\mathbf{R}$ & IN,SU \\
\hline MONIMIACEAE & PE & $A_{0} P$ & A & U & A & A & su \\
\hline MYRTACEAE & PE & $A_{0} P$ & A & B & PO & $\mathbf{R}$ & $\mathbb{N}$ \\
\hline ONAGRACEAE & PE & A & A & B & $\mathrm{PO}$ & $\mathbf{R}$ & $\mathbb{N}$ \\
\hline RUBIACEAE & PE & A & $\mathbf{P}$ & $B, U$ & s & $I_{\mathrm{l}} R$ & $\mathbb{N}$ \\
\hline VERBENACEAE & PE & A & A & B & S & 1 & SU \\
\hline
\end{tabular}

" Abreviaturas: A, ausentes; B, bisexuales; I, irregular; IN, Infero; P, presentes; PO, polipétala; R, regular; S, simpétala; SU, súpero; TR, trinervada y U, unisexuales. 
un importante grupo de géneros endémicos o casi endémicos para México, que se extienden básicamente en México y Guatemala. Estos incluyen a los géneros Asemnanthe (Hooker, 1873); Balmea (Fosberg, 1974); Cigarilla (Aiello, 1979); Cosmocalyx (Standley, 1930); Coutaportla (Breedlove, 1986; Villareal, 1987); Eizia (Standley, 1940); Glossostipula (Lorence, 1986 a); Habroneuron (Darwin, 1980); Hintonia (Bullock, 1935); Omiltemia (Kirkbride, 1984); Pinarophyllon (Brandegee, 1914); Placocarpa (Hooker, 1873); Plocaniophyllon (Brandegee, 1914); Steyermarkia (Standley, 1940) y Stylosiphonia (Brandegee, 1914). Además, es importante destacar que existe un alto porcentaje de endemismo a nivel específico entre las rubiáceas mexicanas.

\section{IMPORTANCIA ECONÓMICA}

La familia Rubiaceae presenta una considerable importancia económica. Sin duda alguna, uno de los productos más importantes es el café (Coffea arabica), una de las bebidas más populares en el mundo. Los alcaloides están notablemente representados dentro de la familia, de manera que no sorprende el hecho de que varias especies presenten propiedades medicinales. Entre éstas deben destacarse el uso de la corteza de Hintonia latiflora, llamada "copalchi" o "palo amargo", que es usada en México para aliviar la fiebre, el paludismo y para expulsar parásitos intestinales. Otros miembros bien conocidos de la familia son la "quinina" (Cinchona spp.), empleada contra el paludismo, la "ipecacuana" (Cephaelis ipecacuanha), usada para inducir vómito y el "madder" (Rubia tinctoria), que fue una especie utilizada antiguamente para la tintura de telas.

Aunado a lo anterior, existen especies conocidas por sus frutos comestibles como los de la "jagua" o "yuale" (Genipa americana), Alibertia edulis, Borojoa patinoi y Vangueria edulis. En la horticultura, algunos géneros como Gardenia, Ixora, Mussaenda, Pentas, Posoqueria y Rondeletia son notables ejemplos de plantas cultivadas por sus flores vistosas y muy fragantes.

\section{ANTECEDENTES}

Definitivamente son escasas las revisiones o monografías que presentan utilidad para la determinación de las rubiáceas mexicanas. No obstante lo anterior, por el momento se cuenta con trabajos sobre los géneros Bouvardia (Blackwell, 1968); Cephaelis (Molina, 1953); Crusea (Anderson, 1972); Deppea (Lorence y Dwyer, 1988); Galium (Dempster, 1978); Hamelia (Elias, 1976); Hoffmannia (Williams, 1973); Lindenia (Darwin, 1976) y Psychotria (Hamilton 1989a, b, c). En la actualidad, las fuentes bibliográficas más utilizadas para la determinación de las rubiáceas de México son las Standley y Williams (1975) y Standley (1926), que incluyen sólo una parte de las especies mexicanas. De menor utilidad al respecto son los trabajos de Shreve y Wiggins (1964) y Standley (1918-1934). 
Además se han publicado listados florísticos en los que se incluye la familia para los estados de Tabasco (Cowan, 1983); Quintana Roo (Sousa y Cabrera, 1983); Chiapas (Breedlove, 1986) y de manera más particular para las Estaciones de campo de Chamela, Jalisco (Lot, 1985) y Los Tuxtlas, Veracruz (Ibarra-Manríquez y Sinaca, 1987). Existe también otro tipo de estudios que se restringen básicamente a describir nuevos taxa (Dempster 1976; Lorence, 1983, 1986 b; Taylor y Lorence, 1985; Lorence y Rodríguez-Acosta, 1986; Breedlove y Lorence, 1987; Lorence y Dwyer, 1987a, 1987b; Lorence y Nee, 1987 y Lorence y Castillo- Campos, 1988; Terrel y Lorence, 1989).

\section{DESCRIPCIÓN DE LA ZONA DE ESTUDIO}

La Sierra de Los Tuxtlas se localiza al SE de Veracruz, formando parte del eje neovolcánico en su porción más oriental (Soto, 1976). Lira y Riba (1984) proporcionan los límites de la Sierra (figura 1).

Geología. Los estudios geológicos describen los materiales más antiguos en la zona como arcillas, tobáceas y areniscas, de grano mediano a grueso, con altos porcentajes de material volcánico, todos provenientes del Oligoceno (Ríos-Macbeth, 1952). Andrle (1964) al comentar sobre la historia geológica de la Sierra concluye que estuvo formada por andesitas y de forma más reciente, por derrames basálticos y tobas del Pleistoceno, mencionándo siete principales centros de erupción en la zona, entre los que destacan los Volcánes de San Martín Pajapan (1270 m), Santa Marta (1550 m) y San Martín Tuxtla $(1660 \mathrm{~m})$. Las altitudes de la región van desde 0 a $1660 \mathrm{msnm}$.

Hidrologia. La red hidrográfica puede dividirse en tres vertientes principales: la vertiente norte, la vertiente central y la vertiente sur-suroeste (Sousa, 1968). Debido a su mayor tamaño, Andrle (1964) destaca los siguientes afluentes: Lago de Catemaco, Laguna de Sontecomapan, así como los ríos Coxcoapan, Guasuntlan, Usuluapan y Yougualtajapan (figura 1).

Suelos. Los suelos encontrados en la Sierra son derivados principalmente de materiales volcánicos (Andrle, 1964). Los suelos de la región presentan características muy variables, debido a la conjunción de las diversas clases de roca madre con los diferentes climas, topografía y tipos de vegetación presentes en la zona. Una comparación de los principales trabajos realizados en la zona puede ser consultada en Ibarra-Manríquez (1985). Para información más detallada sobre el tema, remitirse a Vera y Zapata (1962), Andrle (1964), Flores (1971), Rico y Gómez- Pompa (1976), Alvarez del Castillo (1977) y Chizón (1984).

Clima. El único grupo de climas que está representado en la zona de acuerdo con la clasificación de Koeppen, es el grupo A (cálido-húmedo), el cual es dividido por Soto (1976) en seis diferentes tipos de clima (figura 2). Discusiones más detalladas sobre las características de los climas en la zona son encontradas en Andrle (1964), García (1970) y Soto (1976). 


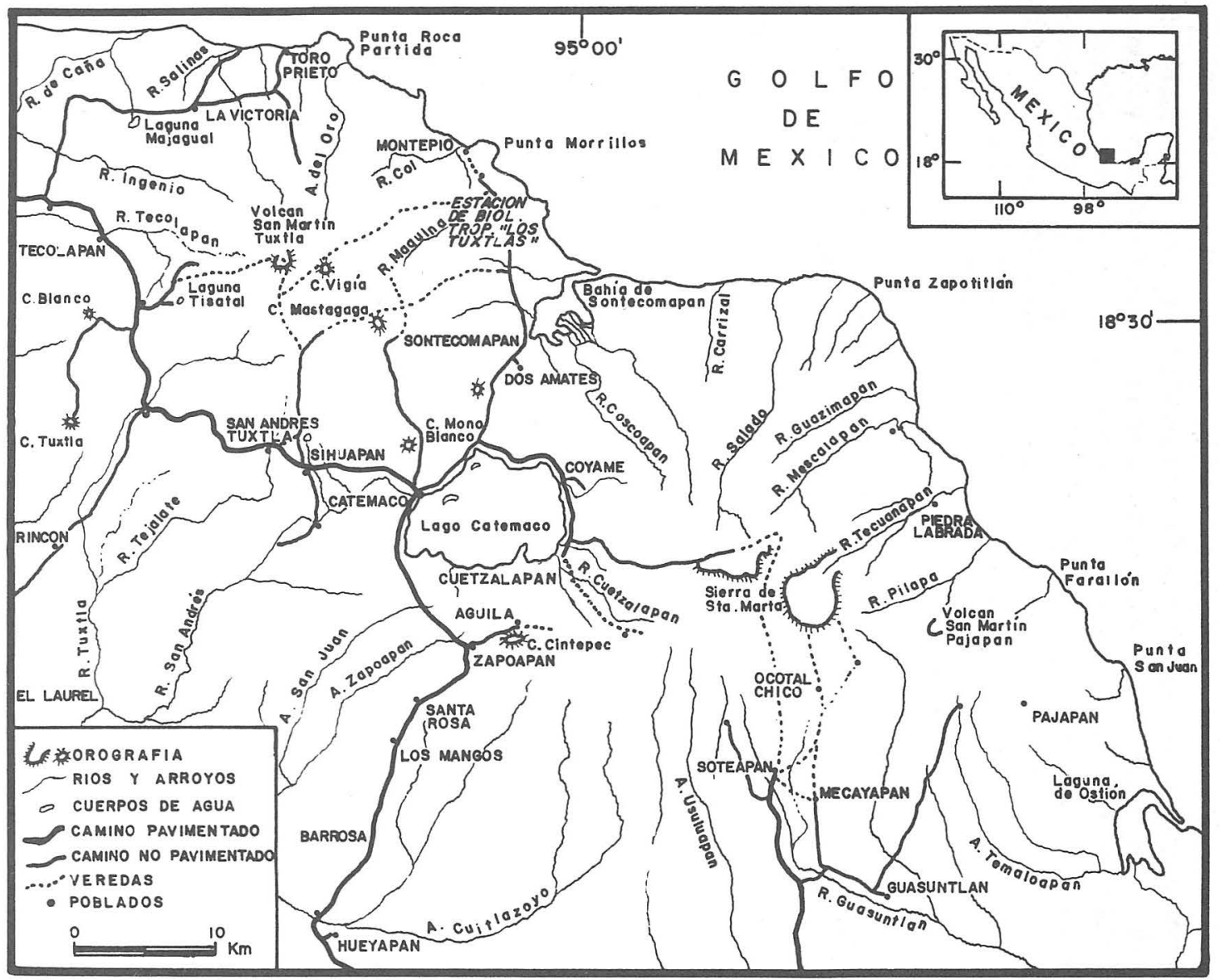

Fig. 2. Climas de la Sierra de "Los Tuxtlas" (tomado de Soto, 1976). 
Vegetación. La sierra de Los Tuxtlas forma parte de la vegetación tropical que se extiende desde Sudamérica a través de Centroamérica y Sureste de México. Andrle (1964) menciona que la dirección y tipo de los vientos, la topografía y los diferentes tipos de suelo conforman un mosaico complejo de vegetación, que se refleja en los 10 diferentes tipos de vegetación presentes en la región (figura 3). Para discusiones sobre la estructura y distribución de éstos tipos de vegetación consultese a Andrle (1964), Ross (1967) y Sousa (1968), los cuales permiten una idea aproximada sobre la riqueza florística de la sierra. Otros trabajos florísticos realizados son los de Alvarez del Castillo (1977), Lira y Riba (1984) e Ibarra-Manríquez y Sinaca (1987).

\section{MetodologíA}

Para la elaboración de la clave de identificación, se procedió a consultar los ejemplares de la familia Rubiaceae, depositados en los Herbarios MEXU (Herbario Nacional) y XAL (Herbario del Instituto Nacional de Investigaciones sobre Recursos Bióticos), colectados en la región de Los Tuxtlas. La clave se diseñó de manera tal que fuera posible determinar una especie con base en el uso de características vegetativas y que no fuera requísito indispensable el contar con flores y frutos de manera simultánea.

En este punto es importante resaltar que la región de Los Tuxtlas ha iido considerada como una de las regiones más interesantes desde el punto de vista florístico, ya que fue uno de los refugios de la vegetación tropical durante los cambios climáticos ocurridos durante el Pleistoceno y que por lo tanto, parece ser un sitio con un alto grado de endemismo en su flora (Toledo, 1982; Wendt, 1987). Aunado a esta particularidad, diversos autores han mencionado la falta de estudios florísticos detallados y a largo plazo, que permitan un adecuado inventario de su flora (Sousa, 1968; Toledo, 1982). Los trabajos de Lira y Riba (1984) e Ibarra-Manríquez y Sinaca (1987), son una muestra reciente de la gran diversidad presente en la zona. Por lo tanto, es conveniente mencionar que el grupo de especies que se encuentran en la clave podría no abarcar a todas las especies presentes en la región. De hecho, en el trabajo se están incluyendo especies que aunque no han sido colectadas hasta el momento, se tiene la plena seguridad de que es posible localizarlas en la zona (en el cuadro 2, estas especies se citan sin ejemplares de respaldo). A pesar de su naturaleza preliminar, el presente trabajo tiene como objetivo central el prover de un instrumento que facilite la identificación y estudio de las rubiáceas de Veracruz, contribuyendo así al conocimiento florístico de la zona y del país.

Finalmente, es necesario enfatizar que existen deficiencias de revisiones taxonómicas en géneros taxonómicamente complejos como Psychotria (subgénero Heteropsychotria), Randia, y Rondeletia. Para otros taxa, sería conveniente una revalidación sobre los caracteres que definen géneros complejos de especies herbáceas, como por ejemplo, en Borreria y Spermacoce. Estas serían algunas de las prioridades para futuras investigaciones de las rubiáceas de México y Mesoamérica. 


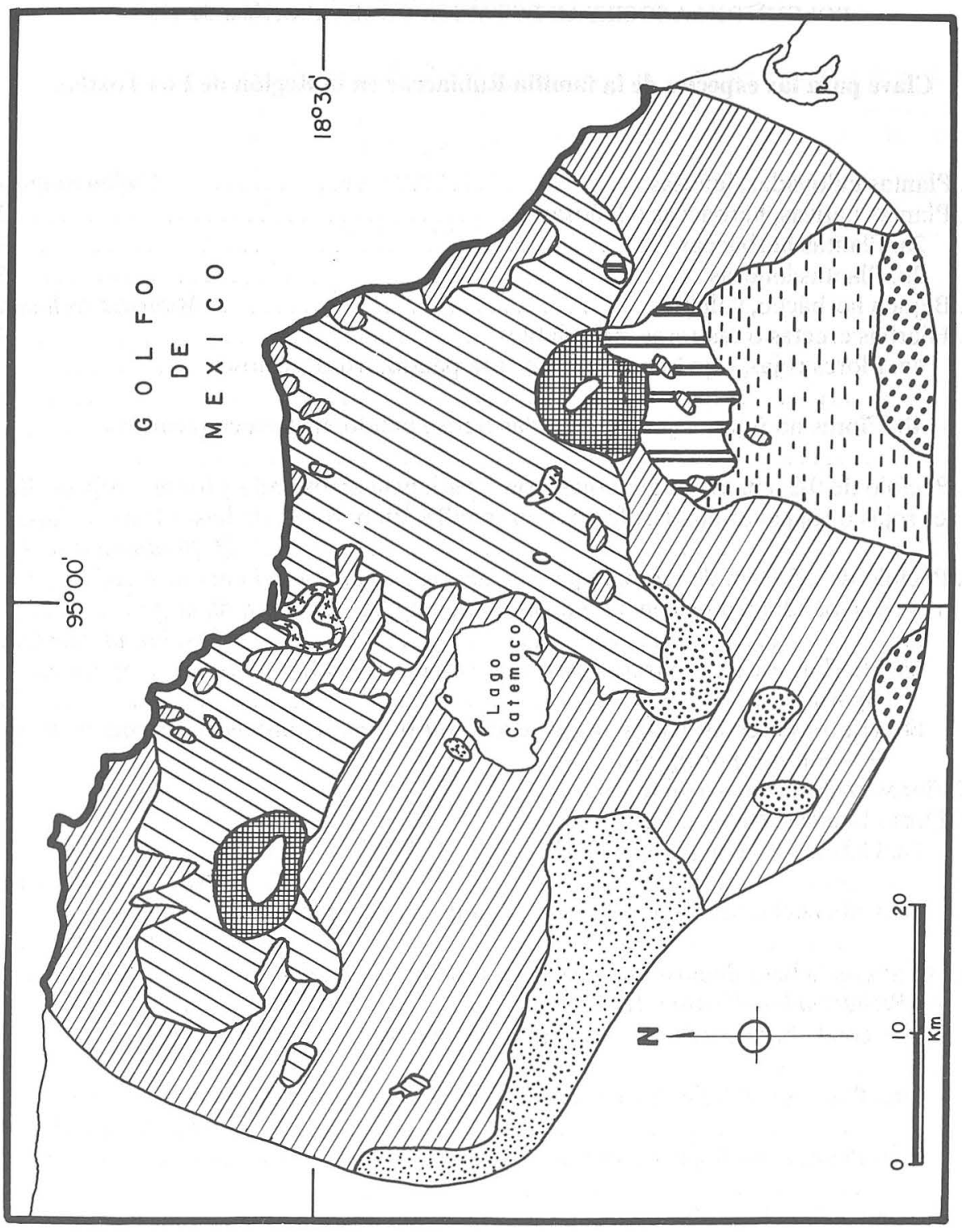

Fig. 3. Tipos de vegetación localizados en la Sierra de "Los Tuxtlas" (modificado de Ross, 1967): bosque

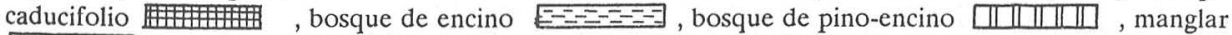

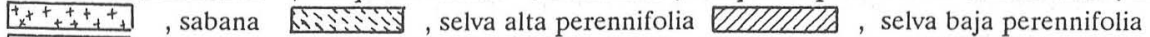
, selva mediana subcaducifolia vegetación costera perturbada 


\section{Clave para las especies de la familia Rubiaceae en la Región de Los Tuxtlas}

1a. Plantas cultivadas, leñosas ......................... Coffea arabica

1b. Plantas nativas, herbáceas o leñosas ........................ 2

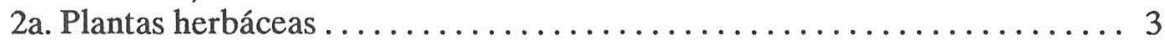

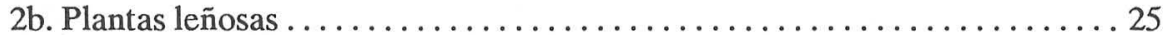

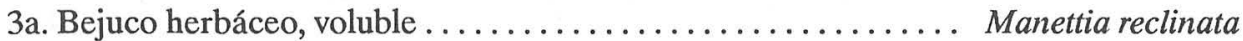

3b. Hierbas erectas o rastreras, no volubles ..................... 4

4a. Flores rojas, rojo anaranjadas o rosa pálido; fruto carnoso. . . . . . . . . .

4b. Flores no rojas, rojo anaranjadas o rosa pálido; fruto seco o carnoso ........

5a. Pecíolo de 0-2 cm de largo; hojas con apariencia arrosetada y tonos rojizos; flores rojas o roja anaranjadas; frutos con semillas numerosas, de hasta $1 \mathrm{~mm}$ de largo Hoffmannia discolor

5b. Pecíolo de 2.5-6 cm de largo; hojas sin apariencia arrosetada ni tonos rojizos; flores rosa pálido; frutos con (1-) 2 semillas, mayores de $2 \mathrm{~mm}$ de largo.

Psychotria uliginosa

6a. Hierbas rastreras; frutos carnosos (excepto Diodiamaritima y Spermacoce

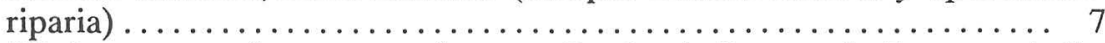

6b. Hierbas erectas; frutos secos (excepto Psychotria limonensis, P. macrophylla y Galium hypocarpum) ............................ . 14

7a. Flores azules; frutos azúl marino ........................ 8

7b. Flores blancas; frutos no azúl marino ....................... 9

8a. Cabezuelas con pedúnculo de 1-4 $\mathrm{cm}$ de largo .

Coccocypselum guianense

8b. Cabezuelas sésiles o subsésiles, con pedúnculo menor de $1 \mathrm{~cm}$ de largo ..... Coccocypselum herbaceum

9a. Hojas con la base decurrente, sésiles (raramente con pecíolos de 2-3 mm de largo en Richardia brasiliensis); fruto seco

9b. Hojas con la base cordada o truncada, pecioladas; fruto carnoso

10a. Plantas con hojas y entrenudos pubescentes; inflorescencias terminales. ...

Richardia brasiliensis

10b. Plantas con hojas y entrenudos glabros; inflorescencias axilare y terminales

11 a. Lámina de la hoja obovada, con estípulas evidentemente fusionadas a manera de una "ocrea", de 3-7 mm de largo; tubo de la corola de 6-7 mm de largo

Diodia maritima

11 b. Lámina de la hoja elíptica y estípulas fusionadas sólo en la base y con la unión de 1-2 mm de largo; tubo de la corola de 2-3 mm de largo.

Spermacoce riparia

12a. Hoja de $2 \mathrm{~cm}$ de largo; flores menores de $2 \mathrm{~mm}$ de largo; frutos menores de $4 \mathrm{~mm}$ de largo 
12b.Hoja mayor de $3 \mathrm{~cm}$ de largo;flores mayores de $3.5 \mathrm{~mm}$ de largo; frutos mayores de $6 \mathrm{~mm}$ de largo.

13a. Inflorescencia desarrollándose a partir del tallo principal o de un tallo secundario, usualmente sin hojas; fruto negro y semillas con la superficie lisa .........

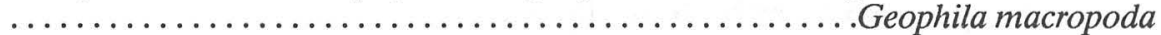

13b. Inflorescencia desarrollándose de un tallo secundario, usualmente con hojas; fruto rojo y semillas con costillas longitudinales

Geophila repens

14a. Hojas de 4-9 cm de ancho; flores mayores de $5 \mathrm{~mm}$ de largo; fruto carnoso

14b. Hojas menores de $3 \mathrm{~cm}$ de ancho; flores menores de $5 \mathrm{~mm}$ de largo (excepto Crusea hispida); fruto seco (excepto Galium hypocarpium pero entonces

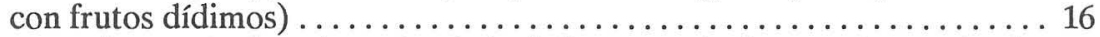

15a. Inflorescencia terminal, pedúnculo de la inflorescencia de 10-15 mm de largo; fruto rojo; hojas ampliamente elípticas, frecuentemente con tonos rojizos al secar Psychotria limonensis

15b. Inflorescencia axilar, pedúnculo de la inflorescencia de 20-50 (-90) mm de largo; fruto blanco; hojas obovadas a elípticas, verde pálidas al secar.

16a. Hojas ovado lineares, 8-10 veces más largas que anchas.

Psychotria macrophylla

16b. Hojas no ovado lineares, $2-4$ veces más largas que anchas Dioidia teres

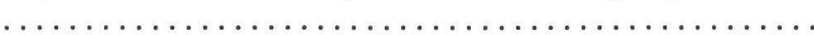
............

17a. Hojas verticiladas, obovadas o raramente elípticas; frutos carnosos, dídimos ... Galium hypocarpium

17b. Hojas no verticiladas o raramente parecidas a esta disposición en algunos nudos y nunca obovadas (excepto Borreria ocymoides); frutos secos, no dídimos .......

18a. Fruto (pixidio) no separándose en mericarpos y con dehiscencia circunsésil Mitracarpus hirtus

18b. Fruto separándose en mericarpos y no con dehiscencia circunsésil .......

19a. Inflorescencia pedúnculada de 4-7 cm de largo; flores de 4-5 mm de largo; fruto dehiscente, con semillas aplanadas, discoides

Hedyotis galeottii

19b. Inflorescencia sésil, de hasta $2 \mathrm{~cm}$ de largo; flores menores de $3 \mathrm{~mm}$ de largo; fruto indehiscente o sí dehiscente, con semillas elipsoides.

20a. Mericarpos indehiscentes

20b. Mericarpos (al menos uno de ellos) dehiscente

21a. Flores blancas; fruto sin un eje persistente. Diodia sarmentosa 21b. Flores lilas; mericarpos separándose a partir de un eje persistente ........... 
32b. Frutos elipsoides, de 15-17 mm de ancho; plantas restringidas a dunas ..... Randia aculeata var. dasyclada

33a. Hojas pubescentes al menos en las venas secundarias del envés; tubo de la corola menor de $1 \mathrm{~mm}$ de ancho; fruto elipsoide, pedicelado

Randia armata

33b. Hojas glabras; tubo de la corola mayor de $1.5 \mathrm{~mm}$ de ancho; fruto esférico, sésil o subsésil .............................. Randia grandifolia 34a. Arboles o arbustos con ramas trepadoras (y en consecuencia, frecuentemente reportados como bejucos leñosos); flores y frutos blancos

34b. Arboles o arbustos sin ramas trepadoras; flores y frutos no exclusivamente blancos ..................................... 36

35a. Hojas con la base cordada a truncada, raramente aguda, margen rovoluto ycoriáceas; plantas de dunas costeras (0-50 msnm)

Chiococca coriacea

35b. Hojas con la base aguda, margen no revoluto, de consistencia variable aunque nunca coriáceas; plantas no restringidas a dunas $[(0-)$ 100-1550 msnm $] \ldots \ldots \ldots$. Chiococca alba 36a. Envés de la hoja y estípula abundantemente blanco pubescente ..........

36b. Envés de la hoja y estípulas glabras y si pubescentes, los tricomas no blancos ni densos .................................... 38 37a.Pecíolo, estípula y envés de la hoja (sobre costa y venas), con pelos largos, vilosos Rondeletia villosa 37b.Pecíolo, estípula y envés de la hoja sin pelos largos ni vilosos, pubescentes........ 38a. Arbustos epífitos (raramente en el suelo, sobre pendientes muy pronunciadas); hojas crasas y venas laterales difíciles de distinguir

38b. Arboles o arbustos no epífitos; hojas no crasas y venas laterales evidentes al menos en una de las caras .......................... 40

39a. Hojas de 1-3 (-4) cm de largo y ápice agudo; tubo de la corola de 1.5-2 mm de largo; frutos carnosos, de (1-) 2 semillas por fruto .

Psychotria guadalupensis

39b. Hojas de (5-) 6-8 cm de largo y ápice obtuso a redondeado; tubo de la corola de $6-8 \mathrm{~cm}$ de largo; frutos secos, con semillas numerosas. . . . . . . . . . . . . . .

Hillia tetrandra 40a. Inflorescencias rodeadas por 3 o más brácteas mayores de $6 \mathrm{~mm}$ de largo, persistentes hasta la fructificación. .................... 41

40b. Inflorescencias no rodeadas por brácteas y si presentes, menores de $5 \mathrm{~mm}$ de largo (excepto Psychotria quinqueradiata pero entonces con hojas sin tonos rojizos al secar, glabras, con frutos rojos) y no persistentes hasta la fructificación. ... 
22a. Cabezuelas con brácteas florales basales ovadas a ligeramente obovadas, pecioladas ...................... Crusea hispida var. hispida

22b. Cabezuelas con brácteas florales basales ovado lanceoladas a lanceoladas, sésiles o subsésiles ....................... Crusea calocephala 23a. Mericarpos dehiscentes en la base ............. Hemidiodia ocimifolia 23b. Mericarpos dehiscentes en el ápice ........................ 24

24a. Semillas transversalmente estriadas; cáliz con 4 lóbulos .

Borreria laevis

24b. Semillas reticuladas a foveoladas; cáliz con 2-3 (-4) lóbulos

Borreria ocymoides

25a. Plantas con espinas (escasas en Randia lonicerioides)

25b.Plantas sin espinas. 34

26a. Bejucos leñosos; hojas hirsuto a menudo pubescentes; frutos verdes. . . . . .

26b.Arboles o arbustos; hojas glabras, en ocasiones escaso puberulentas; frutos no exclusivamente verdes 28

27a.Plantas con espinas reflexas;cáliz de 15-20 mm de largo, hirsuto pubescente y con lóbưlos menores de $1 \mathrm{~mm}$ de ancho, lineares; fruto subesférico a obovoide depreso de hasta $7 \mathrm{~cm}$ de largo y $6 \mathrm{~cm}$ de diámetro

Randia retroflexa

27b. Plantas con espinas rectas; cáliz de $35-40 \mathrm{~mm}$ de largo, sedoso pubescente y con lóbulos de 4-5 mm de ancho, elípticos a obovados; fruto no conocido

28a. Hojas de 1-2.5 cm de largo; tubo de la corola de 18-22 mm de largo ....... Randia lonicerioides 28b. Hojas de (2-) 4-18 cm de largo; tubo de la corola menor de $15 \mathrm{~mm}$ de largo 29

29a. Hojas pubescentes, escabrosas, con tonalidades negruzcas al secar; fruto de 5-6 $\mathrm{cm}$ de largo, menudo pubescente ................. Randia monantha 29b. Hojas glabras (excepto Randia amata que posee venas pubescentes por el envés) no escabrosas (ligeramente en $R$. armata) y tonos verdosos al secar; fruto menor

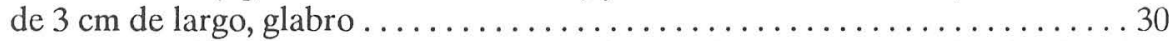
30a. Hojas elípticas u ovado elípticas, ápice agudo, raramente redondeado; frutos blancos ........................... Randia xalapensis

30b. Hojas obovadas u obovado elípticas y con el ápice de forma variable; frutos no blancos (excepto en Randia aculeata var. dasyclada con frutos elipsoi-

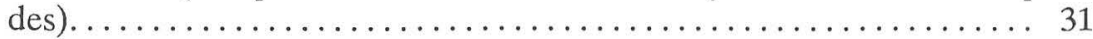

31a. Espinas pareadas; hojas de $8-25 \mathrm{~mm}$ de ancho; tubo de la corola de $3-4 \mathrm{~mm}$ de

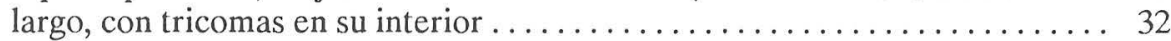

31b.Espinas aparentemente en grupos de 3-4, en realidad pareadas pero con entrenudos muy cercanos entre sí; hojas mayores de $30 \mathrm{~mm}$ de ancho; tubo de la corola

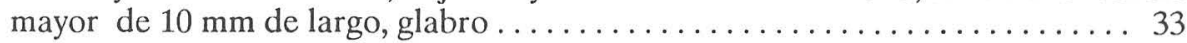

32a. Frutos esféricos a subesféricos, de $8-13 \mathrm{~mm}$ de ancho; plantas de selvas o bosques mesófilos ..................... Randia petenensis 
41a. Hojas. entrenudos y brácteas de la inflorescencia glabros

41b. Envés de la hoja, entrenudos y brácteas de la inflorescencia pubescentes

42a. Hojas obovadas a obovado elípticas, verde rojizas al secar por el envés; brácteas de la inflorescencia verde pálidas a cafés, de 6-10 mm de largo; frutos rojos....................... Psychotria chagrensis

42b. Hojas elípticas, verde pálidas al secar; brácteas de la inflorescencia rojas, naranjas o rosa guindas, de $24-50 \mathrm{~mm}$ de largo; frutos azúl marino.

Cephaelis elata

43a. Hojas elípticas, con pubescencia no ferruginosa; flores amarillas, con brácteas de la inflorescencia rojas o naranjas, de 20-50 mm de largo; frutos azúl marino....

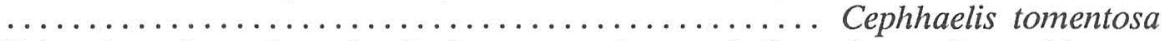
43b. Hojas obovadas u obovado elípticas, con pubescencia ferruginosa; flores blancas, con brácteas de la inflorescencia verdosas, menores de $10 \mathrm{~mm}$ de largo; frutos rojos Psychotria mirandae 44a. Estípulas reniformes (parecidas a una mariposa)

Rondeletia galeottii 44b. Estípulas no reniformes 45

45a. Inflorescencias terminales (también axilares en Deppea purpurascens, peroentonces con flores guindas), con flores no blancas; frutos carnosos (excepto Deppea purpurascens)..

45b. Inflorescencias axilares o terminales, con flores blancas; frutos carnosos o secos

46a. Flores azúl pálido; hojas con el ápice caudado.

46a. Flores azal pálido; hojas con el apice caudado. .

Faramea stenura

46b. Flores no azúl pálido; hojas con ápice no caudado

47a. Flores guindas; frutos secos; hojas obovadas u obovado elípticas, raramente elípticas ............................... Deppea purpurascens 47b. Flores no guindas; frutos carnosos; hojas no obovadas u obovado elípticas.

48a. Estípulas envainantes, con 3-4 aristas en el ápice; frutos azúl obscuros, con (1-) 2 semillas

Palicourea padifolia

48b. Estípulas no envainantes, sin aristas; frutos rojos, con semillas numerosas

49a. Flores amarillas; hojas de (5-) 6.5-13 cm de ancho; frutos subesféricos.

Hamelia longipes

49b. Flores rojas (raramente amarillas); hojas de $2-6 \mathrm{~cm}$ de ancho; frutos elipsoides a

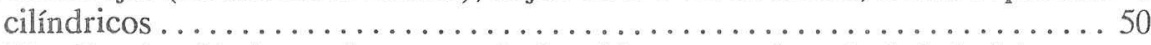

50a. Corola y lámina pubescentes (más evidente por el envés de la hoja)

50b. Corola y lámina glabras............... Hamelia patens var. glabra 51a. Cáliz con 1(-2) sépalo (s) foliáceo (s), unguiculado (s); fruto seco, pubescente Calycophyllum candidissimum 
51b. Cáliz careciendo de sépalos foliáceos y nunca unguiculados; fruto carnoso y si seco, entonces no pubescente....................... 52 52a.Tubo de la corola de 4-15 cm de largo; fruto mayor de $1.5 \mathrm{~cm}$ de largo (excepto Lindenia rivalis) ......................... 53 $52 \mathrm{~b}$. Tubo de la corola menor de $3 \mathrm{~cm}$ de largo; fruto menor de $1 \mathrm{~cm}$ de largo (excepto Genipa americana pero entonces con hojas obovadas u obovada elípticas, secando con tonos azúl negruzcos) $\ldots \ldots \ldots \ldots \ldots \ldots \ldots \ldots$

53a. Hojas de 1-3 cm de ancho; lóbulos del cáliz de 9-11 mm de largo; fruto seco,con semillas de $1-1.5 \mathrm{~mm}$ de largo ................... Lindenia rivalis

53b.Hojas de (3-) 5-11 cm de ancho; lóbulos del cáliz menores de $6 \mathrm{~mm}$ de largo; fruto

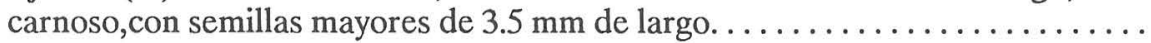

54a. Estípulas caedizas, de 4-6 mm de largo; tubo de la corola de 4-6 cm de largo y de 1-3 (-6) flores porinflorescencia; fruto elipsoide, con costillas longitudinales prominentes ..................... Randia pterocarpa 54b.Estípulas persistentes al menos hasta el segundo par de hojas, de $12-20 \mathrm{~mm}$ de largo; tubo de la corola de 8-12 cm de largo y 8-12 flores por inflorescencia; fruto esférico, con la superficie lisa.............. 55 55a.'rfojas elípticas a ovado elípticas, (1.5-) 2-3 veces más largas que anchas y con el ápice agudo; interior del tubo de la corola glabro excepto en la base; desde $0-450$ msnm.

Posoqueria latifolia

55b.Hojas anchamente ovadas a ovado elípticas u orbiculares, 1-1.5 veces más largas que anchas y con el ápice obtuso; interior del tubo de la corola (al menos de la mitad hacia el ápice) pubescente; desde 800-1400 msnm .

Posoqueria coriacea 56a. Hojas obovadas u obovado elípticas (raramente algunas hojas elípticas en Psychotria quinqueradiata, pero entonces verde grisáceas al secar), de 3-15 $\mathrm{cm}$ de ancho................................ 57

56b. Hojas elípticas u ovado elípticas (ocasionalmente obovado elípticas en Coffea arabica, Chione mexicana y Guettarda macrosperma), de $1.5-8 \mathrm{~cm}$

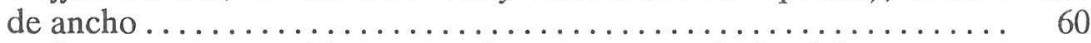

57a. Hojas pubescentes, más evidentes por las venas secundarias del envés. . . . . . . .

57b. Hojas glabras

58a. Tubo de la corola de 4-6 mm de largo; cáliz con lóbulos de 3-5 mm de largo, pubescentes; fruto pubescente, de $5-7 \mathrm{~mm}$ de largo, con semillas numerosas

Sommera arborescens

58b.Tubo de la corola de 1.5 - $2.5 \mathrm{~mm}$ de largo; cáliz con lóbulos de hasta $1 \mathrm{~mm}$ de largo, glabros; fruto glabro, de 3-4 mm de largo, con 1-2 semillas ......

Psychotria erythrocarpa

59a. Hojas de 5-8 cm de largo; flores de 3-4 mm de largo; fruto de 3-4 mm de largo, rojo. . Psychotria quinqueradiata 
59b. Hojas mayores de $10 \mathrm{~cm}$ de largo; flores mayores de $10 \mathrm{~mm}$ de largo; fruto mayor de $30 \mathrm{~mm}$ de largo, café.................... Genipa americana 60a. Flores pubescentes exteriormente (glabrescentes raramente en Alibertia edulis); frutos secos o sí carnosos, con más de 5 semillas .............

60b. Flores glabras exteriormente; frutos carnosos, con 1-2 semillas (excepto Rondeletia ligustroides que tiene frutos con semillas numerosas, pero entonces el tubo de la corola con tricomas amarillos en la garganta)

61a. Cáliz truncado o subtruncado; fruto carnoso, rojo

61b. Cáliz dentado; fruto seco o sí carnoso, no rojo.

Guettarda macrosperma

62a. Lóbulos de la corola de 5-15 mm de largo; frutos carnosos.

62b. Lóbulos de la corola de 1-3 mm de largo; frutos secos.

63a. Hojas con pecíolos glabros; estípulas persistentes, glabras; flores solitarias o en inflorescencias con hasta 12 flores; fruto esférico, de $18-22 \mathrm{~mm}$ de largo, umbi licado.................................. Alibertia edulis

63b. Hojas con pecíolos pubescentes; estípulas caedizas, pubescentes; inflorescencia con más de 20 flores; fruto obovado elipsoide o elipsoide, de 10-13 mm de largo y no umbilicado............................ Amaioua corymbosa 64a. Inflorescencias axilares y ramifloras, raramente terminales, de 3-6 cm de largo; fruto glabro; hojas con el envés glabro ...................

$\ldots \ldots \ldots \ldots \ldots \ldots \ldots \ldots \ldots \ldots \ldots \ldots \ldots \ldots \ldots$ Rondeletia heteranthera

64b. Inflorescencias terminales, de $6.5-15 \mathrm{~cm}$ de largo; fruto pubescente; hoja con el envés pubescente............................. 65

65a. Inflorescencia en forma de espiga, más larga que ancha; fruto esférico; hojas de $1-3 \mathrm{~cm}$ de ancho. .......................... Rondeletia secundiflora 65b. Inflorescencias en forma de tirso o corymbo, igual de larga que ancha; fruto elipsoide; hojas de (3-) 5-10 $\mathrm{cm}$ de ancho.

Rondeletia tuxtlensis 66a. Tubo de la corola con gran cantidad de tricomas en su interior, visibles en

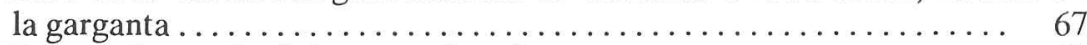

66b. Tubo de la corola glabro en su interior..................... 68

67a. Tubo de la corola de $5-6 \mathrm{~mm}$ de largo, con tricomas amarillos; cápsula seca, café ................................ Rondeletia ligustroides

67b. Tubo de la corola de 1.5-2 mm de largo, con tricomas blancos o translúcidos; baya carnosa, roja .......................... Psychotria clivorum 68a. Inflorescencias terminales o raramente axilares (Coffea arabica); frutos con $1-2$ semillas ..................................... 69 68b. Inflorescencias axilares; frutos con más de 10 semillas (Hoffmannia spp.) 
69a. Tubo de la corola mayor de $12 \mathrm{~mm}$ de largo; frutos azúl obscuro a negros

69b.Tubo de la corola menor de $10 \mathrm{~mm}$ de largo; frutos rojos, blancos o azúl pálido a

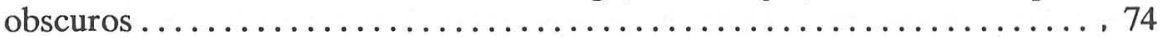
70a. Estípulas persistentes al menos hasta el segundo par de hojas, aristadas, de 12-15 mm de largo; fruto depreso y globoso, con una sola semilla

Faramea occidentalis 70b. Estípulas caedizas y si presentes, no aristadas y menores de $5 \mathrm{~mm}$ de largo; fruto esférico o elipsoide, con (1-) 2 semillas

71a. Inflorescencia con más de 10 flores en antesis de manera simultánea; fruto de 6-7

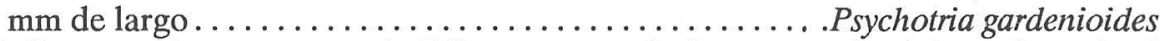

71b. Inflorescencia con menos de 5 flores en antesis de manera simultánea; fruto de 8

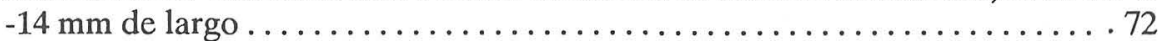
72a. Cáliz de 1.5-2.5 mm de largo; tubo de la corola de 12-18 mm de largo; fruto de $8-10 \mathrm{~mm}$ de largo ....................... Psychotria sousae 72b. Cáliz de 5-6 mm de largo; tubo de la corola de 25-60 mm de largo; fruto de

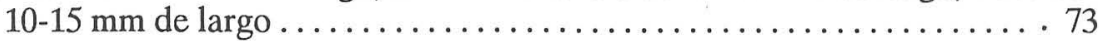

73a.Hojas con ápice caudado, elípticas a ovado elípticas y haz verde grisáceo cuando seco; fruto con la superficie lisa o ligeramente hendido

Psychotria faxlucens

73b. Hojas con el ápice agudo a acuminado, obovadas a elípticas y con el haz verde pálido; fruto 4 costillado.................... Psychotria chiapensis 74a. Inflorescencia con brácteas foliáceas en su base, de 10-15 mm de largo, persistentes hasta la fructificación

Psychotria furcata

74b. Inflorescencia ebrácteada o brácteas si presentes, menores de $5 \mathrm{~mm}$ de largo y no persistentes en la fructificación. ................. 75

75a. Frutos azúl obscuros a morados; inflorescencia pedúnculada (raramente sésil en Palicourea macrantha . . ........................... 76

75b. Frutos rojos o blancos; inflorescencia sésil (aparentando 3-4 (-7) ejes principales e igual número de "inflorescencias"), o pedúnculada.

76a. Estípulas con aristas persistentes al menos hasta el segundo par de hojas. . .

76b. Estípulas con aristas caedizas prontamente.

77a. Estípulas ovadas; hojas de (2.5-)5-7 cm de ancho y negruzcas al secar.

Palicourea macrantha

77b. Estípulas o aristas de éstas líneares; hojas de $1-4 \mathrm{~cm}$ de ancho y verde pálidas o

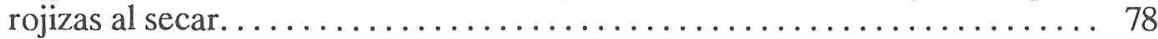
78a.Hojas sésiles o con pecíolos de hasta $3.5 \mathrm{~mm}$ de largoy lámina con tonos rojizos al secar (más evidente en las más terminales); tubo de la corola de 2-3 mm de largo; fruto esférico, de 5-6 mm de largo . 
78b.Hojas nunca sésiles,con pecíolos de 5-11 mm de largo y lámina verdosa al secar; tubo de la corola de 3-7mm de largo; fruto dídimo, de $1.5-2.5 \mathrm{~mm}$ de largo

Psychotria deflexa

79a Inflorescencia de $2-4(-6) \mathrm{cm}$ de largo; tubo de la corola de 6-8.5 mm de largo; fruto ovoide, raramente elipsoide; árboles o arbustos de 2-4 m cuando reproductivos Psychotria luteotuba

79b. Inflorescencia de 6-10 (-15) cm de largo; tubo de la corola de $3.5-4 \mathrm{~mm}$ de largo; fruto esférico; árbol de (5-) 8-15 m cuando reproductivos .

Psychotria simiarum

80a. Inflorescencia de $10-15 \mathrm{~cm}$ de largo . . . . . . . . . . . . . . . 81

$80 \mathrm{~b}$. Inflorescencia de $2-8 \mathrm{~cm}$ de largo..................... 82

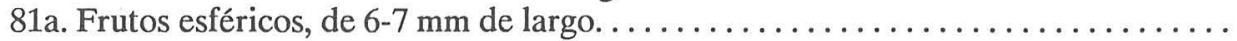

Psychotria costivenia var. costivenia

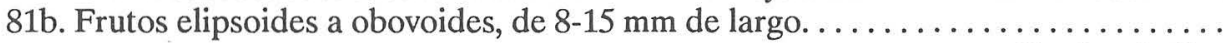

82a.Inflorescencia pedúnculada (un sólo eje principal que porta las flores) ....

Psychotria flava

82b.Inflorescencia sésil, aparentando 3-4 (-7) ejes principales e igual número de "inflorescencias", (raramente pedúnculada, en P. tenuifolia y entonces me-

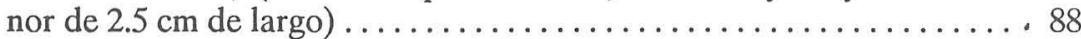

83a. Tubo de la corola de 8-11 mm de largo; frutos blancos

Coussarea mexicana

83b. Tubo de la corola menor de $5 \mathrm{~mm}$ de largo; frutos rojos

84a. Inflorescencias de (6-)10-15 cm de largo; hojas ampliamente elípticas, de $7-10(-13) \mathrm{cm}$ de ancho Psychotria trichotoma 84b. Inflorescencias menores de 5.5. cm de largo; hojas no ampliamente elípticas, menores de $6.5 \mathrm{~cm}$ de ancho.

85a. Tubo de la corola de 3-4 mm de ancho; frutos piriformes o si elipsoides, ligeramente curvos

Chione mexicana

85b.Tubo de la corola de $0.5-1.5 \mathrm{~mm}$ de ancho; frutos sin las características mencionadas anteriormente ................................. 86

86a. Hojas de 2-3 veces más largas que anchas; frutos elipsoides

Psychotria papantlensis

86b. Hojas de (3-) 4 (-5) veces más largas que anchas; frutos esféricos a obovoi-

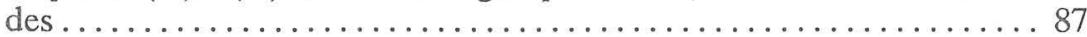

87a.Hojas de 2.5-7 cm de largo; frutos esféricos, de 3-5 mm de largo

Psychotria graciliflora

87b.Hojas de 10-16 cm de largo; frutos esféricos, elipsoides u obovoides, de 7-10 mm

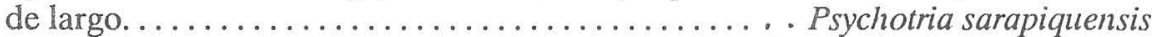
88a. Hojas ampliamente elípticas a ovado elípticas, de 7-10 (-13) cm de ancho, frecuentemente con las venas secando de color blanco por el haz y con ápice caudado a acuminado................. Psychotria trichotoma 
88b. Hojas no ampliamente elípticas, menores de $6.5 \mathrm{~cm}$ de ancho (raramente hasta $8 \mathrm{~cm}$ en Coffea arabica), con venas ocasionalmente secando de color blanco por el haz y ápice no caudado................... 89 89a. Frutos de 10-12 mm de largo, con una línea longitudinal que recorre el fruto; plantas cultivadas, raramente escapadas de cultivo

Coffea arabica

89b. Frutos menores de $7 \mathrm{~mm}$ de largo, con más de 5 líneas longitudinales que recorren el fruto; plantas nativas . .......................... 90 90a. Inflorescencia de 5-9 cm de largo; frutos de 6-7 mm de largo . Psychotria panamensis var. panamensis 90b. Inflorescencia menor de $4.5 \mathrm{~cm}$ de largo; frutos menores de $5.5 \mathrm{~mm}$ de largo

91a. Tubo de la corola de 4-5 mm de largo; fruto esférico, elipsoide o ligeramente pipiriforme ............................ Psychotria mexiae

91b. Tubo de la corola de 2-3 mm de largo; fruto elipsoide

Psychotria tenuifolia

92a. Corola pubescente por su superficie externa; hojas con pubescencia hirsuta

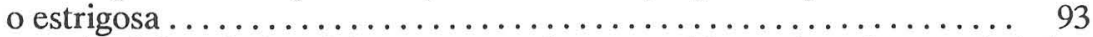

92b. Corola glabra; hojas glabras o con pelos esparcidos sobre el envés de la ho-

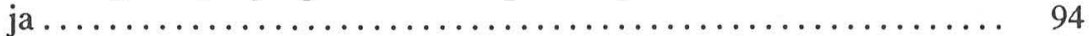

93a. Corola blanca, con su tubo de 7-8 $\mathrm{mm}$ de largo; fruto elipsoide, de $6-8 \mathrm{~mm}$ de largo y 5-6 mm de ancho; hojas de 5-13 cm de largo y $1.5-4 \mathrm{~cm}$ de ancho.......

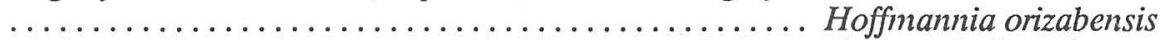
93b.Corola amarillo verdosa, con su tubo de 2-3 mm de largo; fruto esférico, de 2-3 mm de largo y ancho; hojas de 10-25 $\mathrm{cm}$ de largo y $3-8 \mathrm{~cm}$ de ancho. .........

Hoffmannia minuticarpa 94a. Lóbulos del cáliz lineares............... Hoffmannia aff. calycosa 94b. Lóbulos del cáliz triangulares, anchamente triangulares o ausentes .......

95a. Lóbulos del cáliz hasta $0.5 \mathrm{~mm}$ de largo, más anchos que largos, o ausentes, y entonces con el cáliz truncado................. Hoffimannia nicotianaefolia

95b. Lóbulos del cáliz de más de $0.5 \mathrm{~mm}$ de largo, igual o más largos que anchos, siempre presentes y cáliz no truncado..................... 96 96a. Tubo de la corola de $0.5-1.2 \mathrm{~mm}$ de largo; fruto blanco ..............

Hoffmannia altipetens 96b. Tubo de la corola de $2-4 \mathrm{~mm}$ de largo; fruto rosado o rojizo. ...........

97a.Envés de la costa glabro, púrpura-rojizo obscuro; tallos y pecíolos glabros o casi glabros ............................... Hoffmannia conzattii 97b. Envés de la costa viloso-estrigoso, no púrpura rojizo obscuro; tallos y pecíolos estriguloso-viloso ........................... Hoffinannia excelsa 
CUADRO 2. Lista de especies de Rubiaceae localizadas en la región de los Tuxtlas

Alibertia edulis (L. Rich.) A. Rich. ex DC. C 306, I 2365, NyG 156. Amaioua corymbosa H. B. K. C 1804.

Borreria laevis (Lam.) Griseb. D yJ 207, GyR 3953, L 3464, M 1713, 1755.

B. ocymoides (Burm.) DC. L 3463.

JS 9415.

Calycophyllum candidissimum (Vahl) DC. B 159, HB 159, S 2043, 2149, 2301, TP y

Cephaelis elata Sw. C 5163, B 5407, 5853, 6106, MN 18975, 22731, S 3553, SC 153, 743.

C. tomentosa (Aublet) Vahl II 2345, RA 2336.

Coccocypselum herbaceum Lam. SH 163.

C. guianense (Aubl.) K. Schum. II 2352, AVyRH 58.

Coffea arabica L. I 19, R 1385, RB 7554.

Coussarea mexicana Standley CT 1, JB 209.

Crusea calocephala DC. B 5526, CTyC 53, CV 402, M 1763, NyG 880, R 1360, S 2388.

C. hispida (Miller) Robinson var. hispida CT 340, GHyA 20399, IySC 2796, L 3324, M 2017.

Chiococca alba (L.) Hitch. AL 337, B 5228, RH 672.

C. coriacea Mart. \& Gal. C 1640, L 4971, 4972, LG 44, N 2457.

Chione mexicana Standley B 6067, CT 282, 2830, IySC 1945, P 144, SC 256.

Deppea purpurascens Lorence B 5301, C 11593, 11849, F 8304, L 4141, MN 19865, SC 388.

Diodia maritima Thonning ex Schumocher G 5488, WB 3196.

D. sarmentosa Sw. $\mathbb{R} 1376$.

D. teres Walt. M 2095.

Faramea occidentalis (L.) A. Rich. B 5129, C 1076, 1386, 1430, CT 196, I 950, 1976, 2137, IySC 1174, 2231, L 3112, 3309, 3930, SC 223.

F. stenura Standley B 5189, 5610, 5841, 6116, CT 425, 2893, MN 18788, 19938.

Galium hypocarpium (L.) Endl. ex Griseb. ByAC 5338, C 565.

Genipa americana L. BD 1764, II 983, 1754, 2411.

Geophila macropoda (Ruiz \& Pavón) DC. C 600, RH 1260.

G. repens (L.) I. M. Johnston C 2803, 2868.

Guettarda macrosperma J. D. Smith S 2733.

Hamelia longipes Standley AV 108, B 6437, C 286, I 129, 1565, 1791, 2112, L 3473, 3475.

H. patens Jacq. var. glabra Oersted C 1610, L 3492, 4966, GD 9322.

H. patens Jacq. var. patens CT 2506, RH 39, SG 4.

Hedyotis galeottii (Martens) Terrel \& Lorence

Hemidiodia ocimifolia (Willd.) K. Schum. Ly RA 3321, R 1318, 1799. 
CUADRO 2. Continuación

Hillia tetrandra Sw. B 6105, I 1381, 1739, M 3075, MCH 448, MN 18764, RH 1256. Hoffmania altipetens Dwyer, inédita. B 5179, 5381, CT 2901, I 812, 1946, 2127, 2822, MNyGS 19869, SC 822.

$H$. aff. calycosa J. D. Smith B 6186, I 1785, 2507, SC 823 .

H. conzattii B. L. Robinson B 5806, AVyRH 53.

H. discolor Hemsl. B 6130, CT 65, DyJ 43, I 1031, 1414, L 4142, SC 159, 523.

H. excelsa (Kunth in H.B.K.) K. Schum.

H. minuticarpa Dwyer, inédita. CT 1280, I 2983, 3119, SC 531.

H. nicotianaefolia (Mart. \& Gal.) L. O. Wms.

H. orizabensis Standley C 5172.

Lindenia rivalis Benth. CH 199, HB 16, GQ 1429, WB 3185.

Manettia reclinata L. C 1598, IySC 1086, 2849, 2914, WyA 20941.

Mitracarpus hirtus (L.) DC. LG 142, M 2100, S 126, 2550,

Nertera granadensis (L. f.) Druce ByAC 5392.

Palicourea padifolia (M. Martens) Taylor \& Lorence B 5363, 5595, 5771, 5974, 5988, 6001, P 70, S 3023, 3467.

P. macrantha Loes. B 5443, C 5140 .

Posoqueria coriacea Mart. \& Gal. C 844, SC 171.

P. latifolia (Rudge) R. \& S. BV 29, I 963, L 3322, P 181, TW 3327.

Psychotria clivorum Standley \& Steyerm. II 1162.

P. costivenia Griseb. var. costivenia S 4434.

P. chagrensis Standley C 1273, CT 45, 2858, I 658, 998, 1619, 1755, 2150, 2424, L 3467.

P. chiapensis Standley B 6170, I 37, 55, 651, 809, 1113, 1341, 1507, 1545, 1758, 2219, L 3320.

P. deflexa DC. G 5423.

P. erythrocarpa Schldl. C 1564, CT 2431.

P. faxlucens Lorence \& Dwyer B 6360, 6397, C 236, 391, 499, 767, CT 152, 257, 285, I 519, 579, IySC 1464, 1720, 1721, 2113, L 3279, 3280, 3474, 3484.

P. flava Oersted ex Standley B 5162, 6081, C 166, 688, 721, CT 2821, II 1159, 1613, 2128, L 3487, S 3358.

P. furcata A. DC.

P. gardenioides (Scheidw.) Standley B 5949, C 1508, CT 2509, F 8296, GQ 1522, M 1700 .

P. graciliflora Benth. in Oersted B 5310, CTyC 162.

P. guadalupensis (DC.) Howard B 5417, 5418, 6237.

P. limonensis K. Krause B 6205, 6448, I 1118, 1834, 2487, L 3479, JP 1441, JR 20348.

P. luteotuba Lorence B 6124, 6140, I 2347, L 4143, MN 18799.

P. macrophylla Ruiz \& Pavón FV 12179, IySC 2823, W 20961. 


\section{CUADRO 2. Continuación}

P. mexiae Standley B 5364, 5410, 5513, 5594, 5772, 5976, 6187, CT 2, N 8401.

P. mirandae C. Hamilton B 6094, DyJ 93, LP 1946.

P. panamensis Standley var. panamensis B 5564, 6391, 6007, C 5181, CT 420, I 98, L 4138, MNyGS 19927, 19997, S 2104, 3615.

P. papantlensis (Oersted) Hemsley. B 5190, C 1037, CT 155, CH 206, I 22, 1119 , 1582, 1600, 2212, 2379, L 3284, 3471, 4960, 4963.

P. quinqueradiata Polak. B 6183, C 157, FM 114.

P. sarapiquensis Standley B 5307, CT 2829, JF 50, II 1162, 1173, 1574, 2355, 2463, 2850, MCH 417, SC 225.

P. simiarum Standley C 5, 12, 231, 1312, CT 49, 202, I 1479, JF 51, L 3283, 3498, R 1227.

P. sousae Lorence B 5995, C 5090, S 3614.

P. tenuifolia Sw. HB 116, 208, L 3478.

P. trichotoma Mart. \& Gal. B 5513, 6007, CT 2471, N 903.

P. uliginosa Sw. B 5221, 5309, 5611, 5847.

P. veracruzensis Lorence \& Dwyer B 5212, 5302, 6068, 6117, C 102, 450, FV 5872, I 1463, 1589, 2508, L 3282, 3313, 3480, 3916, 4958, 4959, 4961, MN 18801, 22567, 22771.

Randia aculeata L. var. dasyclada Steyerm. L 3323,4970, 4973, 4974, S 3401.

$R$. armata (Sw.) DC. B 6289, CT 2459.

$R$. grandifolia (J. D. Smith) Standley AGyEL 32284, L 3300, 3493, S 4493.

R. lonicerioides Dwyer \& Lorence B 5191.

$R$. monantha Benth. B 5229.

$R$. petenensis Lundell S 3108.

R. pterocarpa Lorence \& Dwyer B 5150, 6402, C 811, CT 2967, G 5118, I 97, 365, $516,864,1109,1329,2389,2810$, L 3316.

$R$. retroflexa Lorence \& Nee C 1038, CT 217, I 89, 388, 1904, 2239, 2390, L 4135, 4957, MN 22529, 22597, 22673.

$R$. vazquezii Lorence \& Dwyer,. B 6206, CT 244.

R. xalapensis Mart. \& Gal. B 5312, C 591, I 1575, 2130, L 3490, 4962, SC 379.

Richardia brasiliensis Gómez NyG 874. SC 387.

Rondeletia buddleioides Benth. C 1073, 1476, I 1326, 1817, 2018, 2216, LyRA 3494,

R. galeottii Standley B 6057, C 718, F 8307, I 1327, 1743, 2827, L 3304, SC 192.

$R$. heteranthera Brandegee

R. ligustroides Hemsl.

R. secundiflora Robinson B 5248, C 958, CT 406.

R. tuxtlensis Lorence \& Castillo-Campos. B 6003, C 10904, 11183, 11283, 11424, CT 2881, MN 18785, SC 155, 772.

R. villosa Hemsl. CT 248, DyJ 44 . 
CUADRO 2. Continuación

Sommera arborescens Schldl. B 5348, C 74, CT 283, I 1798, 1818, 1940, 1942, SC 792.

Spermacoce riparia Cham. \& Schldl. GHyA 20356.

Abreviaturas para los colectores de los ejemplares de respaldo: A (W. S. Armbruster), AC (Carlos Alvarez del Castillo), AG (Al Gentry), AL (Antonio Lot), AV (A. Villegas), B (John H. Beaman), BD (Brigada Dioscóreas), BV (Brigada Vázquez), C (Ismael Calzada), CH (Carol Horvitz), CT (Refugio Cedillo Trigos), CV (Carlos VázquezYanez), D (R. Dressler), EL (Emily Lott), F (Faustino Miranda), FM (Fernando Meléndez), FV (Fernando Ventura), G (Arturo Gómez-Pompa), GD (G. Davidse), GH (G. Holstein), GQ (Lauro González Quintero), GS (George Schatz) HB (Helia Bravo), I (Guillermo Ibarra Manríquez), J (Quentin Jones), JB (Joséfina Barajas), JF (José Flores), JP (Jackie M. Poole), JR (Jerzy Rzedowski), JS (José Sarukhán), L (David H. Lorence), LG (Liliana Gutiérrez Carbajal), LP (L. Paray), M (Guadalupe Martínez Calderộn), MCH (Miguel Cházaro), MN (Michael Nee), N (Lorin Nevling), P (M. Ponce), R (Marino Rosas), RA (Thennilapurama P. Ramamoorthy), RB (Robert Bye), RH (Rafael Hernández Magaña), S (Mario Sousa Sánchez), SC (Santiago Sinaca Colín), SG (Sergio Guevara), SH (Gary Shapiro), TP (T.D. Pennington), TW (Thomas L. Wendt), V (Mario Vázquez Torres), W (Grady L. Webster) y WB (Wolfgang Boege).

AGRADECIMIENTOS. Deseamos expresar nuestro reconocimicnto al Sr. Felipe Villegas por su disposición para la elaboración de las figuras de este trabajo y a los curadores de los Herbarios MEXU y XAL, las facilidades para la consulta del material de Rubiaceae depositado en los acervos de dichos Herbarios. Finalmente, nuestro agradecimiento a Rodolfo Dirzo, Armando Butanda y dos revisores anónimos, quienes aportaron valiosas sugerencias para mejorar el manuscrito. Las correciones aportadas por Abisaí García Mendoza, Laura González García, Esteban Martínez y Clara H. Ramos fueron de gran utilidad para la elaboración de la clave de determinación presentada en este estudio.

\section{LITERATURA CITADA}

AIELLO. A. 1979. A reexamination of Porlandia (Rubiaceae) and associated taxa. J. Arnold Arbor. 60:38-126.

ALVAREZ DEL CASTILLO, G. C. 1977. Estudio ecológico y florístico del cráter del volcán de San Martín Tuxtla, Ver. México. Biotica 2(1):3-54.

ANDRLE, R F. 1964. A blogeographical investigation of the Sierra of Los Tuxtlas. Tesis Doctoral. Lousiana State University. University microfilms, Ann Arbor, Michigan. 236p.

ANDERSON, W. R. 1972. A monograph of the genus Crusea (Rubiaceae). Mem. New York Bot. Gard. 22(4):1-128.

BLACKWELL, W. H. Jr. 1968. Revision of Bouvardia (Rubiaceae). Ann. Missouri BoL Gard. 55:1-30. BRANDEgeE, T. S. 1914. Plantae Mexicanae Purpusianae, VI. Unit: Calif. Publ. Bot. 6(4):68-71. 
BREEDlovE, D. E. 1986. Listados Morísticos de México IV. Flora de Chiapas. Instituto de Biología, Universidad Nacional Autónoma de México, México. 246p.

BREEDLOVE, D. E. y D. H. LORENCE. 1987. New species of Deppea (Rubiaceae) from Chiapas. Phytologia 63(1):43-47.

BULLOCK, A. A. 1935. Tabula 3295. Hintonia latiflora var. leiantha Bullock. Hooker's Icones Plantarum 3:Tab. 3295.

COWAN, C. P. 1983. Listados norísticos de México I. Flora de Tabasco. Instituto de Biología, Universidad Nacional Autónoma de México, México. 123p.

CHIZON, S. E. 1984. Relación suelo-vegetación en la Estación de Biología Tropical Los Tuxtlas, Ver. (un análisis de la distribución de los diferentes tipos de suelo en relación con la cubierta vegetal que soporta). Tesis. Escuela Nacional de Estudios Profesionales Zaragoza, Universidad Nalcional Autónoma de México, México. 66p.

DARWIN, S. P. 1976. The genus Lindenia (Rubiaceae). J. Arnold Arbor. 57(4):426-449.

DARWIN, S. P. 1980. Habroneuron Standley, a little known genus of Mexican Rubiaceae. Brittonia 32:343-347.

DEMPSTER, L. T. 1976. Galium mexicanum (Rubiaceae) of Central American and Western North America. Madroño 23(7):378-386.

DEMPSTER, L. T. 1978. The genus Galium (Rubiaceae) in Mexico and Central America. Univ. Calif. Publ. Bot. 73:1-33.

ELIAS, T. S. 1976. A monograph of the genus Hamelia (Rubiaceae). Mem. New York Bot. Gard. 26(4):81-144.

FLORES, J. S. 1971. Estudios de la vegetación del Cerro El Vigía de la Estación de Biología Tropical Los Tuxtlas, Veracruz Tesis. Facultad de Ciencias. Universidad Nacional Autónoma de México, México. 66p.

FOSBERG, F. R. 1974. Studies in American Rubiaceae 2. Ayuque, Balmea stormae, an endangered Mexican specics. Sida 5:268-270.

GARCIA, E. 1970. Los climas del estado de Veracruz (según el sistema de clasificación climático de Koppen, modificado por la autora). An. Inst. Biol. Univ. Nal. Autón. México. Ser. Bot. 41(1):3-42.

HAMILTON, C. W. 1989 a. A revision of Mesoamerican Psychotria subgenus Psychotria (Rubiaceae), Part I: Introduction and species 1-16. Ann. Missouri Bot. Gard. 76(1):67-111.

HAMILTON, C. W. 1989 b. A revision of Mesoamerican Psychotria subgenus Psychotria (Rubiaceae), Part II: Species 17-47. Ann. Missouri Bot. Gard. 76(2):67-111.

HAMILTON, C. W. 1989 c. A revision of Mesoamerican Psychotria subgenus Psychotria (Rubiaceae), Part III: Species 48-61 and appendices. Ann. Missouri Bot. Gard. 76(3):886-916.

HAMPSHIRE, R. J. y D. A. SUTTON. 1988. Flora mesoamericana. A preliminary bibliography of the mesoamerican fora. Antony Rowe LTD, Chippenham, Wiltshire, Great Britain. 194p.

HEYWOOD, V. H. 1985. (Edr.). Las plantas con Mores. Reverté, Barcelona. 332p.

HOOKER, J. D. 1873. Rubiaceae. En: Bentham, G. y J. D. Hooker, Genera Plantarum 2:7-151.

IBARRA-MANRÍQUEZ, G. 1985. Estudios preliminares sobre la flora leñosa de la Estación de Biología

Tropical Los Tuxtlas, Veracrux, México. Tesis. Facultad de Ciencias, Universidad Nacional Autónoma de México, México. 264p.

IBARRA-MANRÍQUEZ, G. y S.C. SINACA. 1987. Listados Florísticos de México VII. Estación de Biología Tropical Los Tuxilas, Veracruz Instituto de Biología, Universidad Nacional Autónoma de México, México. 51p.

KIRKBRIDE, J. H. Jr. 1984. Review of Omiltemia (Rubiaceae). Syst. BoL. 9:410-414.

LEE, Y. S. y R. M. RINK. 1985. Remarks on the chromosome numbers in the Rubiaceae. Phytologia 57(1):73-79.

L.JRA, R. y R. RIBA. 1984. Aspectos fitogeográficos y ecológicos de la Flora Pteridofita de la Sierra de Santa Marta, Veracruz, México. Biolica 9(4):451-467. 


\section{RUBIACEAE EN LOS TUXTLAS}

LORENCE, D. H. 1983. First record of Elaeagia (Rubiaceae) in México, with description of a new species, E. uxpanapensis. Bol. Soc. Bot. México 45:65-69.

LORENCE, D. H. 1986 a. Glossostipula (Rubiaceae), a new genus from Mexico and Guatemala. Candollea 41:453-461.

LORENCE, D. H. 1986 b. The identity of Portlandia guatemalensis (Rubiaceae). Syst. Bot. 11:209-213.

LORENCE, D. H. y J. D. DWYER. 1987 a. New taxa and a new name in Mexican and Central American Randia (Rubiaceae, Gardenieae). Bol. Soc. Bot. México 47:37-48.

LORENCE, D. H. y J. D. DWYER. 1987 b. New taxa in Mexican Psychotria (Rubiaceae, Psychotrieae). Bol. Soc. Bot. México 47:49-64.

LORENCE, D. H. y J. D. DWYER. 1988. A revision of Deppea (Rubiaceae). Allertonia 4 (7):389-436.

LORENCE, D. H. y G. CASTILLO-CAMPOS. 1988. Tres nuevas especies y una nueva combinación en el género Rondeletia (Rubiaceae, Rondeletieae) de Veracruz y Oaxaca, México. Biótica 13:147-157.

LORENCE, D. H. y M. NEE. 1987. Randia retroflexa (Rubiaceae), a new species from southern Mexico. Brittonia 39:371-375.

LORENCE, D. H. y M. RODRIGUEZ-ACOSTA. 1986. Randia guerrerensis, una nueva especie de Rubiaceae de México. Biotica 11(3):195- 199.

LOTT, E. J. 1985. Listados Florísticos de México III. La Estación de Biología Chamela, Jalisco. Instituto de Biología, Universidad Nacional Autónoma de México, México. 47p.

MIRANDA, F. y E. X. HERNÁNDEZ. 1963. Los tipos de vegetación de México y su descripción. Bol. Soc. Bot. México 28:29-178.

MOLINA, R. A. 1953. Revisión de las especies de Cephaelis (Rubiaceae) de México, Centroamérica y Las Antillas. Ceiba 4(1):1-38.

RICO B., M. F. y A. GÓMEZ-POMPA. 1976. Estudio de las primeras etapas sucesionales de una selva alta perennifolia en Veracruz, México. En: Gómez-Pompa, A. et al. (Edrs.) Investigaciones sobre la regeneración de selvas altas en Veracruz, México. CECSA, México. pp:112-202.

RÍOS-MACBETH, F. 1952. Estudio geológico de la región de Los Tuxtlas, Veracruz. Asoc. Mex. Geol. Peirol. Bol. 4:325-376.

ROSS, G. N. 1967. A distributional study of the butterflies of The Sierra de Tuxtla in Veracruz, Mexico. Tesis Doctoral. Lousiana State University. 246p.

RZEDOWSKI, J. 1978. Vegetación de México. Limusa, México. 432p.

SHREVE, F. y I. L. WIGGINS. 1964. Vegetation and Mora of the Sonoran Desert. Stanford University Press, California. 2v.

SOTO, E. M. 1976. Algunos aspectos climáticos de la región de Los Tuxtlas, Veracruz. En: Gómez-Pompa, A. et al. (Edrs.) Investigaciones sobre la regeneración de selvas altas en Veracruz, México. CECSA, México. pp:70-110.

SOUSA S., M. 1968. Ecología de las leguminosas de Los Tuxtlas, Veracruz. An. Inst. Biol. Univ. Nal. Autón. México. Ser. Bot. 39:121-160.

SOUSA S., M. y E. F. CABRERA. 1983. Listados forísticos de México II. Flora de Quintana Roo. Instituto de Biología, Universidad Nacional Autónoma de México, México. 100p.

STANDLEY, P. C. 1918-1934. Rubiales. Rubiaceae (pars). North Amer. I. 32 (1-4):1-300.

STANDLEY, P. C. 1926. 158. Rubiaceae. Madder family. En: Trees and Shrubs of Mexico. Contr. U. S. Nat. Herb. 23 (5):1349-1394.

STANDLEY, P. C. 1930. Studies of American Plants. III. Contr. Field Mus. Nat. Hist. Bot. Ser. 8:3-73.

STANDley, P. C. 1940. Studies of American Plants IX. Publ. Field. Mus. Nat. Hist. Bot. Ser. 22:3-62.

STANDLEY, P. C. y L. O. WILLIAMS. 1975. Rubiaceae. En: Flora of Guatemala. Fieldiana Bot. 24 part 11(1-3):1-274.

TAYLOR, C. y D. H. LORENCE. 1985. Lectotypification of Palicourea galeottiana M. Martens (Rubiaceae) and a new name for this common spccies. Taxon 34:667-669.

TERREL, E. E. y D. H. LORENCE. 1989. Hedyotis galeottii (Rubiaceac), new combination for a mexican species. Phytologia 66(1):1-4. 
TOLEDO, V. M. 1982. Pleistocene changes of vegetation in tropical Mexico. En: Prance, G. T. (Edr.)

Biological diversification in the Tropics. Columbia Univ. Press, New York. pp:93-111.

VERA y ZAPATA, R. 1962. Estudio físico y químico de algunos suelos del estado de Veracruz Tesis. Escuela Nacional de Ciencias Biológicas, Instituto Politecnico Nacional, México. 76p.

VILLAREAL, Q., J. A. 1987. Coutaportla pailensis (Rubiaceae), a new species from Coahuila, México. Sida 12:223-225.

WENDT, T. 1987. Las selvas de Uxpanapa, Veracruz-Oaxaca, México: evidencia de refugios florísticos Cenozoicos. An. Inst. Biol. Univ. Nal. Autón. México., Ser. Bot. (número único) 58:29-54 :29. 54. WILliAMS, L. O. 1973. Hoffmannias from Mexico and Central America. Fieldiana BoL 36 (6):51-60. 